\title{
Outgoing Longwave Radiation due to Directly Transmitted Surface Emission
}

\author{
S. M. S. COSTA \\ Center for Weather Forecasts and Climate Studies, National Institute for Space Research, Cachoeira Paulista, Brazil \\ K. P. SHINE \\ Department of Meteorology, University of Reading, Reading, United Kingdom
}

(Manuscript received 22 September 2011, in final form 22 December 2011)

\begin{abstract}
A frequently used diagram summarizing the annual- and global-mean energy budget of the earth and atmosphere indicates that the irradiance reaching the top of the atmosphere from the surface, through the midinfrared atmospheric window, is $40 \mathrm{~W} \mathrm{~m}^{-2}$; this can be compared to the total outgoing longwave radiation (OLR) of about $235 \mathrm{~W} \mathrm{~m}^{-2}$. The value of $40 \mathrm{~W} \mathrm{~m}^{-2}$ was estimated in an ad hoc manner. A more detailed calculation of this component, termed here the surface transmitted irradiance (STI), is presented, using a lineby-line radiation code and 3D climatologies of temperature, humidity, cloudiness, etc. No assumption is made as to the wavelengths at which radiation from the surface can reach the top of the atmosphere. The role of the water vapor continuum is highlighted. In clear skies, if the continuum is excluded, the global- and annualmean STI is calculated to be about $100 \mathrm{~W} \mathrm{~m}^{-2}$ with a broad maximum throughout the tropics and subtropics. When the continuum is included, the clear-sky STI is reduced to $66 \mathrm{~W} \mathrm{~m}^{-2}$, with a distinctly different geographic distribution, with a minimum in the tropics and local peaks over subtropical deserts. The inclusion of clouds reduces the STI to about $22 \mathrm{~W} \mathrm{~m}^{-2}$. The actual value is likely somewhat smaller due to processes neglected here, and an STI value of $20 \mathrm{~W} \mathrm{~m}^{-2}$ (with an estimated uncertainty of about $\pm 20 \%$ ) is suggested to be much more realistic than the previous estimate of $40 \mathrm{~W} \mathrm{~m}^{-2}$. This indicates that less than one-tenth of the OLR originates directly from the surface.
\end{abstract}

\section{Introduction}

Summary diagrams of the components of the globaland annual-mean earth energy budget are popular for illustrating our general understanding for those inside and outside the atmospheric sciences. The diagrams produced by Kiehl and Trenberth (1997, hereafter KT97) and updated by Trenberth et al. (2009) have been particularly widely used and are invaluable summaries of current understanding, and provide a useful framework for discussing remaining uncertainties.

This short article is intended to be a pedagogical discussion of one component of the KT97 figure [which was not updated in Trenberth et al. (2009)], which is the amount of longwave radiation labeled "atmospheric

Corresponding author address: S. M. S. Costa, Satellite and Environmental Division, Center for Weather Forecasts and Climate Studies, National Institute for Space Research, Rod Presidente Dutra Km 40, Cachoeira Paulista, SP, Brazil.

E-mail: simone.sievert@cptec.inpe.br window." KT97 estimate this component to be $40 \mathrm{~W} \mathrm{~m}^{-2}$ compared to the total outgoing longwave radiation (OLR) of $235 \mathrm{~W} \mathrm{~m}^{-2}$; however, KT97 make clear that their estimate is "somewhat ad hoc" rather than the product of detailed calculations. The estimate was based on their calculation of the clear-sky OLR in the 8-12- $\mu \mathrm{m}$ wavelength region of $99 \mathrm{~W} \mathrm{~m}^{-2}$ and an assumption that no such radiation can directly exit the atmosphere from the surface when clouds are present. Taking the observed global-mean cloudiness to be $62 \%$, their value of $40 \mathrm{~W} \mathrm{~m}^{-2}$ follows from rounding $99 \times(1-0.62)$.

KT97 note that the $40 \mathrm{~W} \mathrm{~m}^{-2}$ "emphasizes that very little radiation is actually transmitted directly to space as though the atmosphere were transparent," which implies that they consider the term to be radiation originating from the surface. (KT97, earlier in the paragraph, are a little vaguer about the term, noting that it represents radiation that "originates near [our emphasis] the earth's surface".) We show here that more detailed calculations indicate that the likely value is around half of KT97's estimate. The reason is that while the midinfrared 
atmospheric window is relatively transparent, it is not entirely so, primarily because of absorption by the water vapor continuum (e.g., Bignell 1970; Clough et al. 1989). The major component of the continuum in the window is the self-continuum (resulting from interactions between water vapor molecules) whose strength scales as the square of the vapor pressure. Hence its importance varies strongly with latitude and is particularly important in the tropics. KT97's calculations were based on a single atmosphere (a modified form of the U.S. Standard Atmosphere); while they did not account for any possible effects of this nonlinearity we will show that, in the global mean, it is not a serious source of error.

Presumably the reason why KT97, and others, have not explicitly calculated this term is that the methods of vertical integration of the radiative transfer equation in most radiation codes compute the net effect of surface emission and absorption and emission by the atmosphere, rather than each component separately. In the calculations presented here we explicitly calculate the upward irradiance at the top of the atmosphere due to surface emission: we will call this the surface transmitted irradiance (STI). We are not aware of any previous detailed global-scale calculations of the STI. We account for the spatial variation of this component and do not assume that the overcast sky component is zero. In addition, unlike KT97, we make no assumption as to the wavelengths at which radiation can reach directly reach space from the surface. Although the STI is indeed largely confined to the midinfrared window, the $18-25-\mu \mathrm{m}$ region also becomes relatively transparent in drier atmospheres (e.g., Petty 2006).

\section{Methods and data}

Clear-sky STI $\left(\mathrm{STI}_{\mathrm{clr}}\right)$ is calculated by using the lineby-line model Reference Forward Model (RFM) version 4.22 (Dudhia 1997) in the wavenumber domain $10-3000 \mathrm{~cm}^{-1}$ (wavelengths $3.33-1000 \mu \mathrm{m}$ ) at a spectral resolution of $0.005 \mathrm{~cm}^{-1}$. The version of RFM used here incorporates the Clough-Kneizys-Davies (CKD) water vapor continuum model (version 2.4); although this has been superseded by the MT-CKD model, the changes in the midinfrared window (see, e.g., Firsov and Chesnokova 2010) are rather small and unlikely to change our estimate by more than $1 \mathrm{~W} \mathrm{~m}^{-2}$. The strength of the midinfrared continuum and its temperature dependence are in any case subject to revision as new measurements refine our understanding (e.g., Baranov et al. 2008).

Irradiances are calculated at a spatial resolution of $10^{\circ}$ latitude and longitude using a climatology of annualmean profiles of pressure, water vapor, temperature, and cloudiness described in Christidis et al. (1997). Although slightly dated, the global-mean column water amount is within about $1 \%$ of more recent climatologies. Carbon dioxide, methane, and nitrous oxide are assumed to be well mixed with mixing ratios of $365,1.72$, and 0.312 ppmv, respectively. Other greenhouse gases are not considered since their radiative forcing is less than $0.4 \mathrm{~W} \mathrm{~m}^{-2}$ (e.g., Solomon et al. 2007; Schmidt et al. 2010); we have performed an approximate estimate of the effect of 1 ppbv of chlorofluorocarbon 12 (CFC12) (to approximate the sum of all halocarbons in the atmosphere) on the $\mathrm{STI}_{\mathrm{clr}}$ and the effect is less than $1 \%$. Likewise, aerosols are not considered. It is the larger mineral dust particles that are more likely to have an impact in this spectral region; estimates of the impact of aerosol on the OLR are typically around $0.5 \mathrm{~W} \mathrm{~m}^{-2}$ (e.g., Schmidt et al. 2010). The impact on the STI will depend on, for example, the height of aerosol layers and the aerosol radiative properties and is likely a larger effect than the CFCs if they are mostly at lower altitudes; this is discussed further in section 4 . The surface is assumed to have an emittance of unity.

To calculate the total STI, clouds needs to be included. We neglect any scattering in the longwave [see Costa and Shine (2006) for more discussion] so that the STI at wavenumber $\nu$ is given by

$$
\begin{aligned}
\operatorname{STI}(\nu)= & \operatorname{STI}_{\text {clr }}(\nu)\left(1-\sum_{i=1}^{9} A_{i}\right) \\
& +\sum_{i=1}^{9} A_{i} \operatorname{STI}_{\mathrm{clr}}(\nu) \exp \left[-1.66 k(\nu) \mathrm{WP}_{i}\right]
\end{aligned}
$$

where $A$ and WP respectively correspond to cloud amount and water path from the nine cloud types from the International Satellite Cloud Climatology Project (Rossow and Schiffer 1999). The mass absorption coefficient $k(\nu)$ is calculated using standard Mie scattering code assuming a lognormal distribution of cloud droplet sizes for water clouds and using Fu et al. (1998) for ice clouds. The irradiance field is assumed to be diffuse, and so a standard diffusivity parameter of 1.66 is adopted. Clearly a more sophisticated approach to modeling the STI component through cloud could be adopted; however, our method is considerably more complex than that of KT97 and, in any case, it will be shown that clear skies dominate the total STI.

\section{Results}

We first illustrate the STI using a single STI $_{\text {clr }}$ globalmean profile, constructed from the 3D climatology. Figure 1a shows three components of the longwave 

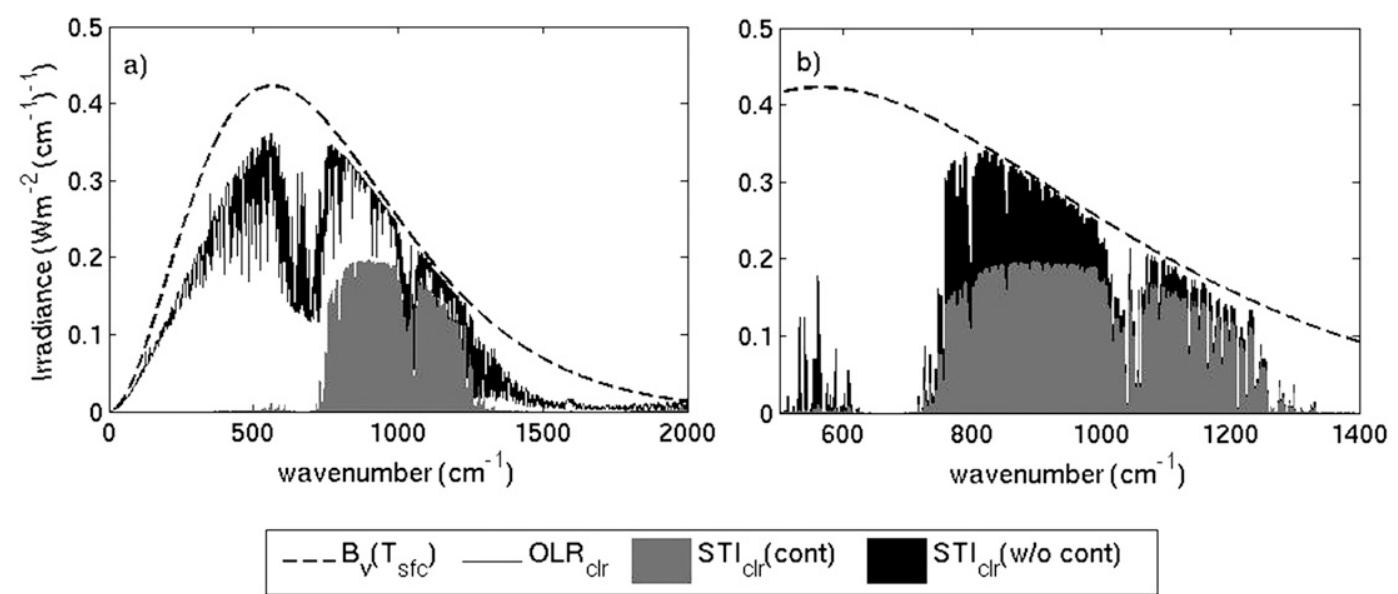

FIG. 1. Spectral distribution of the clear-sky Earth Radiation Budget components $\left[\mathrm{W} \mathrm{m} \mathrm{m}^{-2}\left(\mathrm{~cm}^{-1}\right)^{-1}\right]$ using a global-mean atmosphere. (a) Longwave irradiance emitted by surface $B_{\nu}\left(T_{\text {sfc }}\right)$ assuming it to be a blackbody, the outgoing longwave radiation $\left(\mathrm{OLR}_{\mathrm{clr}}\right)$, and surface transmitted irradiance including the water vapor continuum $\left[\mathrm{STI}_{\mathrm{clr}}\right.$ (cont)]. (b) As in (a), over a smaller wavenumber interval, but includes, instead of OLR clr $_{\text {, the surface }}$ transmitted irradiance when the water vapor continuum is excluded $\left[\mathrm{STI}_{\mathrm{clr}}\right.$ (w/o cont)].

radiation budget as function of wavenumber: surface emitted irradiance (given by the Planck function, because we assume the surface to be a blackbody) (dashed line), the upward irradiance at the top of the atmosphere derived using RFM, including the absorption and emission by the atmosphere (solid line), and the $\mathrm{STI}_{\text {clr }}$ (gray bars). The spectrally integrated irradiance emitted by the surface is about $386 \mathrm{~W} \mathrm{~m}^{-2}$, of which $65 \mathrm{~W} \mathrm{~m}^{-2}$ is $\mathrm{STI}_{\mathrm{clr}}$. The OLR is about $259 \mathrm{~W} \mathrm{~m} \mathrm{~m}^{-2}$, indicating that the net effect of emission and absorption by atmospheric gases is to contribute $194 \mathrm{~W} \mathrm{~m}^{-2}$ to the OLR.

Figure 1a shows clearly that, for the global mean profile, the STI is predominantly through the midinfrared window (as assumed by KT97), which is shown in more detail in Fig. 1b. However, it is also clear from the difference between the dashed line and the gray bars that a considerable proportion (around $50 \%$ at $800 \mathrm{~cm}^{-1}$ ) of the radiation leaving the surface is absorbed by the atmosphere even in this window. To illustrate the role of the water vapor continuum, the black bars in Fig. 1b show $\mathrm{STI}_{\text {clr }}$ when the continuum is turned off. In the absence of continuum absorption, almost all surface emitted radiation reaches the top of the atmosphere through the atmospheric window, except in the ozone bands near $1000 \mathrm{~cm}^{-1}$. In addition, when the continuum is excluded, a contribution to the $\mathrm{STI}_{\mathrm{clr}}$ can be seen in Fig. 1 b, at $500-600 \mathrm{~cm}^{-1}$, outside of what is normally termed the window. In this no-continuum case the $\mathrm{STI}_{\text {clr }}$ is $96 \mathrm{~W} \mathrm{~m}^{-2}$ (quite close to KT97's estimate of $99 \mathrm{~W} \mathrm{~m}^{-2}$ ), which is $50 \%$ greater than the case when the continuum is included $\left(65 \mathrm{~W} \mathrm{~m}^{-2}\right)$.

Figure 2 shows the geographical distribution of annual-mean $\mathrm{STI}_{\text {clr }}$ without and with the continuum and

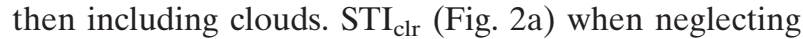
the continuum is highest in the tropics and subtropics, peaking at $124 \mathrm{~W} \mathrm{~m}^{-2}$, and decreases toward the poles to around $70 \mathrm{~W} \mathrm{~m}^{-2}$. When the continuum is included (Fig. 2b), there is a marked change in the geographical distribution. The minimum is now in the tropics, with values falling as low as $37 \mathrm{~W} \mathrm{~m}^{-2}$, with local maxima away from the equator, most notably in subtropical desert regions. The continuum absorption is so strong in the tropics that $\mathrm{STI}_{\text {clr }}$ in polar regions (which is only modestly influenced by the continuum) is typically $40 \%$ higher than the tropical values.

Figure 3 shows the zonal and annual mean of the $\mathrm{STI}_{\text {clr }}$ to emphasize the role of the continuum. The STI $_{\text {clr }}$ neglecting the continuum (dash-dotted line) is generally more than $80 \mathrm{~W} \mathrm{~m}^{-2}$ at all latitudes, with maxima in the northern subtropics (mostly associated with the Sahara desert), but with little latitudinal gradient throughout the tropics and subtropics; the tropical values are reduced by more than $50 \%$ when the continuum is included (dashed lines). The effect of the continuum clearly diminishes outside of the tropics and is responsible for only around a $10 \%$ reduction in $\mathrm{STI}_{\mathrm{clr}}$ at high latitudes.

Interestingly, these more detailed calculations yield global-mean values of $\mathrm{STI}_{\mathrm{clr}}$ of 66 and $100 \mathrm{~W} \mathrm{~m}^{-2}$, with and without the continuum, very close to the values ( 65 and $99 \mathrm{~W} \mathrm{~m}^{-2}$ ) computed using the single global-mean profile, in spite of the potential nonlinearities due to the vapor pressure-squared dependence of the selfcontinuum.

It is emphasized that the impact of the continuum on the OLR is much smaller than its impact on $\mathrm{STI}_{\mathrm{clr}}$. 

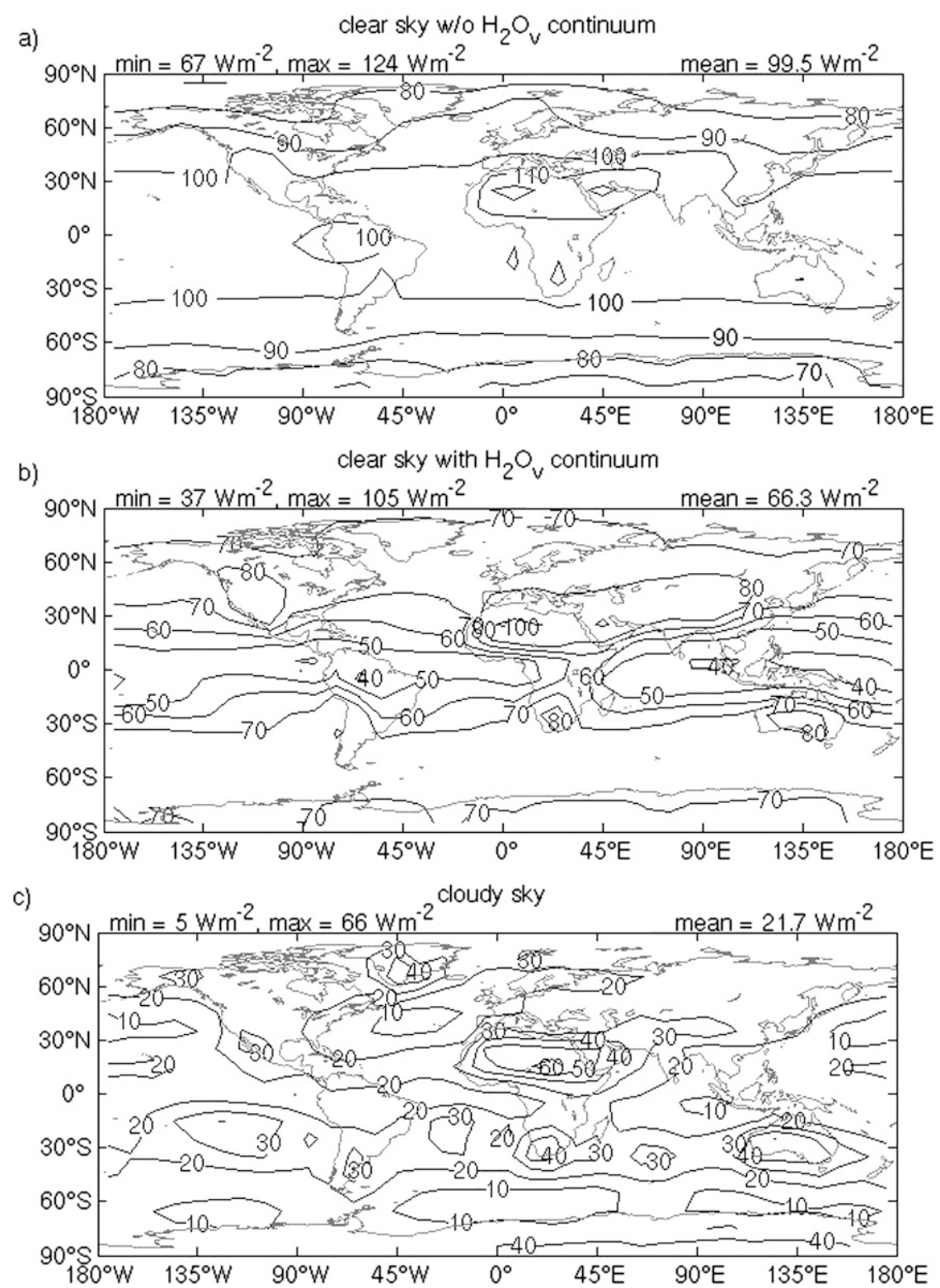

FIG. 2. Geographical distribution of the annual-mean surface transmitted irradiance ( $\mathrm{W} \mathrm{m}^{-2}$ ) for (a) clear skies without the continuum, (b) clear skies with the continuum, and (c) cloudy skies. Above each panel, the minimum, maximum, and global-mean values are shown.

For the OLR, the reduction in the irradiance reaching the top of the atmosphere directly from the surface (i.e., the STI) due to the continuum is largely compensated by increased atmospheric emission by the continuum. In our calculations, the annual- and global-mean $\mathrm{OLR}_{\mathrm{clr}}$ is $271 \mathrm{~W} \mathrm{~m}^{-2}$ without and $262 \mathrm{~W} \mathrm{~m}^{-2}$ with the continuum, broadly consistent with the tabulated values in Ellingson et al. (1991). Figure 4 shows the zonal- and annual-mean impact of the continuum on the OLR (together with the observed Earth Radiation Budget Experiment (ERBE) $\mathrm{OLR}_{\mathrm{clr}}$ for comparison; see, e.g.,
Barkstrom et al. 1989). The effect of the continuum peaks at around $14 \mathrm{~W} \mathrm{~m}^{-2}$ near the equator, compared with the impact on $\mathrm{STI}_{\mathrm{clr}}$ of around $70 \mathrm{~W} \mathrm{~m}^{-2}$ (see Fig. 3). In relative terms, the effect of the continuum is much smaller for the $\operatorname{OLR}_{\mathrm{clr}}$ ( $8 \%$ reduction) than for $\mathrm{STI}_{\mathrm{clr}}$ (32\% reduction).

When including clouds, the STI is reduced further (Fig. 2c) because clouds absorb strongly throughout the infrared window. In regions of high cloud amount, such as the midlatitude storm tracks, the STI is reduced from a clear-sky value of $70 \mathrm{~W} \mathrm{~m}^{-2}$ to less than $10 \mathrm{~W} \mathrm{~m}^{-2}$. 


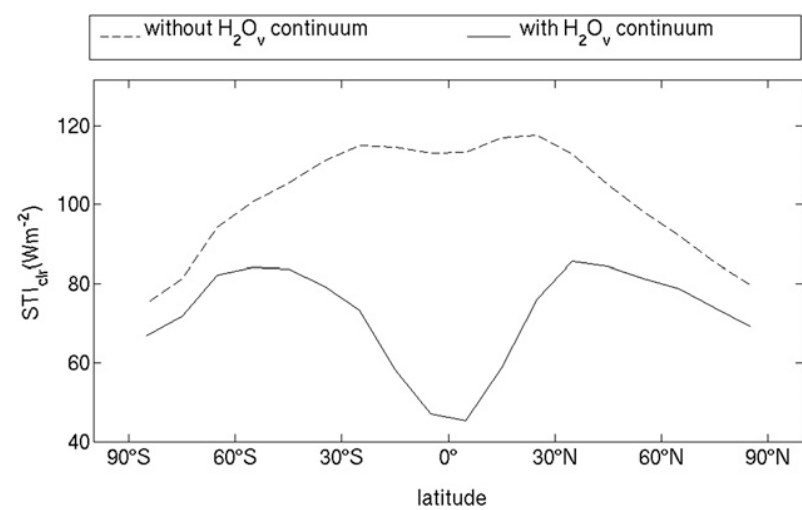

FIG. 3. Zonal and annual mean of the clear-sky surface transmitted irradiance $\left(\mathrm{W} \mathrm{m}^{-2}\right)$ with (solid line) and without (dashed line) the water vapor continuum.

As expected, values are less affected in desert regions. The subtropics are now the main source of the globalmean STI. The effect of clouds is to reduce the STI from its clear-sky value of $66 \mathrm{~W} \mathrm{~m}^{-2}$ by two-thirds to a value of about $22 \mathrm{~W} \mathrm{~m}^{-2}$. Indeed, just considering global means, had we adopted KT97's assumption that overcast regions contribute nothing to the STI, then, using Rossow and Schiffer's (1999) global and annual-mean cloud amount of $67 \%$ and an $\mathrm{STI}_{\mathrm{clr}}$ value of $66 \mathrm{~W} \mathrm{~m}^{-2}$, this would have yielded almost exactly our cloudy-sky value.

\section{Discussion}

This study presents what we believe to be the most detailed estimate of the surface contribution to the clear and cloudy-sky OLR. This contribution is called the surface transmitted irradiance (STI). The global- and annualmean STI is found to be $22 \mathrm{~W} \mathrm{~m}^{-2}$. The purpose of producing the value is mostly pedagogical and is stimulated by the value of $40 \mathrm{~W} \mathrm{~m}^{-2}$ shown on the often-used summary figures produced by KT97 and Trenberth et al. (2009).

The key reason for the difference between our and KT97's values is their assumption that all of the clear-sky radiation at the top of the atmosphere in the $8-12-\mu \mathrm{m}$ window originated from the surface; we show that the opacity associated with the water vapor continuum in the 8-12- $\mu \mathrm{m}$ window significantly reduces the clear-sky STI (globally by around 30\% compared to a no-continuum value, and even more in moist tropical regions). Our work has also shown that other assumptions used by KT97, including the use of a single global-mean profile, the assumption that the contribution to the STI in overcast regions is negligible and that the STI is predominantly in the $8-12-\mu \mathrm{m}$ window are, at least for the global mean, well justified.

Our value could be refined by including, for example, other components (halocarbons, aerosols), different
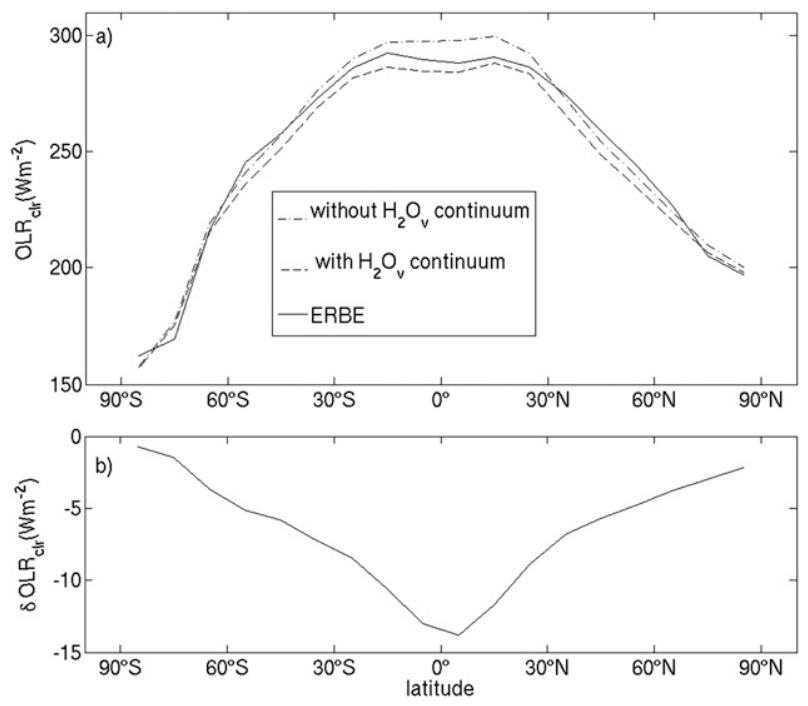

FIG. 4. (a) Zonal- and annual-mean clear-sky outgoing longwave radiation (OLR) $\left(\mathrm{W} \mathrm{m}^{-2}\right)$ observed by ERBE (solid line) and calculated with the continuum (dashed line) and without it (dot-dashed). (b) The continuum minus no-continuum difference in the OLR.

representations of the water vapor continuum, and scattering and inhomogeneities in clouds. The impact of aerosols may be quite large. Schmidt et al. (2010) give a top-of-atmosphere forcing value of $0.5 \mathrm{~W} \mathrm{~m}^{-2}$. Assuming that the aerosol is mostly at low altitude and given that we find the continuum causes a change in $\mathrm{STI}_{\mathrm{clr}}$ several times larger than the $\mathrm{OLR}_{\mathrm{clr}}$, by analogy the effect of aerosols on STI may be of order 1-2 $\mathrm{W} \mathrm{m}^{-2}$. Our assumption that the surface emits as a blackbody could also be examined, using emerging datasets on the spectral variation of the surface emittance (which can deviate significantly from unity and be as low as 0.75 in the 1000-1200- $\mathrm{cm}^{-1}$ spectral region, in desert regions; e.g., Zhou et al. 2011; Vogel et al. 2011). Some decision would need to made, then, as to whether or not infrared radiation reflected by surfaces with emittances less than zero should be included in the STI term as this reflection partially compensates for the reduced emission. Although locally important, the effect of nonunity emittances on the global-mean STI is likely to be only a few percent.

Our value could also clearly be refined by using more modern climatologies of (in particular) water vapor and cloudiness and by performing calculations at high spatial and temporal resolution. We do not expect the globalmean STI to be significantly sensitive to the spatial and temporal resolution, given that we found that the STI derived using the single global-mean profile differed little from our more detailed calculation. Recent estimates of global-mean total column water vapor have not deviated more than around 5\% from "textbook" values of about $25 \mathrm{~kg} \mathrm{~m}^{-2}$ (e.g., Sudradjat et al. 2005) although 
differences in the details of the distribution are larger. Cloudiness is likely a larger source of error in our calculations because of the inherent difficulties in producing and evaluating global cloud climatology products (see, e.g., Kahn et al. 2008). Stubenrauch et al. (2009) estimate, using a preliminary assessment of nine global cloud climatologies, that the true global-mean cloud amount is $70 \% \pm 5 \%$; if it is assumed that no STI originates from cloudy regions (see section 3 ), then the consequent uncertainty in the clear-sky fraction translates into an uncertainty of STI of about $\pm 20 \%$.

Given the neglect of other gases and aerosols, and of nonunity emittances, we argue that our derived value is likely to be an overestimate of the true value. Hence we recommend that in any updates to summary energy budget figures, a rounded-down value of $20 \mathrm{~W} \mathrm{~m}^{-2}$ for the STI be used, with an estimated uncertainty of about $20 \%$ mostly due to clouds. For clear skies, $65 \mathrm{~W} \mathrm{~m}^{-2}$ is probably an appropriate value. It would be less ambiguous to label this component as something like "emission from surface" rather than "atmospheric window" as was done in KT97 to make it clear that the term refers to where in the climate system the energy originates (i.e., from the surface) rather than the wavelength region in which it originates (the atmosphere and clouds also emit irradiance in the window and the $20 \mathrm{~W} \mathrm{~m}^{-2}$ does not represent this emission).

Within the context of the KT97 energy-balance type of figures, any adjustment in one quantity necessitates a consideration of how other components in the same figure may be affected. Since the OLR $\left[235 \mathrm{~W} \mathrm{~m}^{-2}\right.$ in KT97 and $239 \mathrm{~W} \mathrm{~m}^{-2}$ in Trenberth et al. (2009)] and the longwave cloud radiative forcing $\left(30 \mathrm{~W} \mathrm{~m}^{-2}\right)$ are reasonably well constrained by observations, we recommend that the "loss" of $20 \mathrm{~W} \mathrm{~m}^{-2}$ from the STI term means that the term labeled by KT97 as "emitted by atmosphere" should be increased from 165 to $185 \mathrm{~W} \mathrm{~m}^{-2}$ in KT97 and from 169 to $189 \mathrm{~W} \mathrm{~m}^{-2}$ in Trenberth et al. (2009). We note that Trenberth and Fasullo (2012), in a recent update to their energy balance diagram, already adopt our value of $22 \mathrm{~W} \mathrm{~m}^{-2}$, and they give a value of $187 \mathrm{~W} \mathrm{~m}^{-2}$ for the "emitted by atmosphere" term.

Acknowledgments. KPS acknowledges support from the NERC/EPSRC consortium CAVIAR. We thank the reviewers for their comments.

\section{REFERENCES}

Baranov, Y. I., W. J. Lafferty, Q. Ma, and R. H. Tipping, 2008: Water-vapor continuum absorption in the $800-1250 \mathrm{~cm}^{-1}$ spectral region at temperatures from 311 to 363 K. J. Quant. Spectrosc. Radiat. Transfer, 109, 2291-2302, doi:10.1016/j.jqsrt. 2008.03.004.
Barkstrom, B., and Coauthors, 1989: Earth Radiation Budget Experiment (ERBE) archival and April 1985 results. Bull. Amer. Meteor. Soc., 70, 1254-1262.

Bignell, K. J., 1970: The water-vapour infra-red continuum. Quart. J. Roy. Meteor. Soc., 96, 390-403.

Christidis, N., M. D. Hurley, S. Pinnock, K. P. Shine, and T. J. Wallington, 1997: Radiative forcing of climate change by CFC-11 and possible CFC replacements. J. Geophys. Res., 102, 19 597-19 609.

Clough, S. A., F. X. Kneizys, and R. W. Davies, 1989: Line shape and the water vapor continuum. Atmos. Res., 23, 229-241.

Costa, S. M. S., and K. P. Shine, 2006: An estimate of the global impact of multiple scattering by clouds on outgoing long-wave radiation. Quart. J. Roy. Meteor. Soc., 132, 885-895, doi:10.1256/ qj.05.169.

Dudhia, A., 1997: Reference Forward Model v3 software user's manual. Tech. Rep. ESA POMA-OXF-GS-0003, European Space Agency, 89 pp.

Ellingson, R. G., J. Ellis, and S. Fels, 1991: The intercomparison of radiation codes used in climate models: Long wave results. J. Geophys. Res., 96 (D5), 8929-8953.

Firsov, K. M., and T. Y. Chesnokova, 2010: Sensitivity of downward long-wave radiative fluxes to water vapor continuum absorption. Atmos. Oceanic Opt., 23, 462-468, doi:10.1134/S1024856010060059.

Fu, Q., P. Yang, and W. B. Sun, 1998: An accurate parameterization of the infrared radiative properties of cirrus clouds for climate models. J. Climate, 11, 2223-2237.

Kahn, B. H., and Coauthors, 2008: Cloud type comparisons of AIRS, CloudSat, and CALIPSO cloud height and amount. Atmos. Chem. Phys., 8, 1231-1248.

Kiehl, J. T., and K. E. Trenberth, 1997: Earth's annual global mean energy budget. Bull. Amer. Meteor. Soc., 78, 197-208.

Petty, G. W., 2006: A First Course in Atmospheric Radiation. Sundog Publishing, $460 \mathrm{pp}$

Rossow, W. B., and R. A. Schiffer, 1999: Advances in understanding clouds from ISCCP. Bull. Amer. Meteor. Soc., 80, 2261-2287.

Schmidt, G. A., R. A. Ruedy, R. L. Miller, and A. A. Lacis, 2010: Attribution of the present-day total greenhouse effect. J. Geophys. Res., 115, D20106, doi:10.1029/2010JD014287.

Solomon, S., D. Qin, M. Manning, M. Marquis, K. Averyt, M. M. B. Tignor, H. L. Miller Jr., and Z. Chen, Eds., 2007: Climate Change 2007: The Physical Science Basis. Cambridge University Press, 996 pp.

Stubenrauch, C., and Coauthors, 2009: Assessment of global cloud climatologies. GEWEX Newsletter, No. 19, International GEWEX Project Office, Silver Spring, MD, 6-7. [Available online at http://www.gewex.org/images/Feb2009.pdf.]

Sudradjat, A., R. R. Ferraro, and M. Fiorino, 2005: A comparison of total precipitable water between reanalyses and NVAP. J. Climate, 18, 1790-1807.

Trenberth, K. E., and J. T. Fasullo, 2012: Tracking earth's energy: From El Niño to global warming. Surv. Geophys., doi:10.1007/ s10712-011-9150-2, in press.

$\longrightarrow,-$, and J. Kiehl, 2009: Earth's global energy budget. Bull. Amer. Meteor. Soc., 90, 311-323.

Vogel, R. L., Q. Liu, Y. Han, and F. Weng, 2011: Evaluating a satellite-derived global infrared land surface emissivity data set for use in radiative transfer modeling. J. Geophys. Res., 116, D08105, doi:10.1029/2010JD014679.

Zhou, D. K., A. M. Larar, X. Liu, W. L. Smith, L. L. Strow, P. Yang, P. Schlüssel, and X. Calbet, 2011: Global land surface emissivity retrieved from satellite ultraspectral IR measurements. IEEE Trans. Geosci. Remote Sens., 49, 1277-1290. 
Copyright of Journal of the Atmospheric Sciences is the property of American Meteorological Society and its content may not be copied or emailed to multiple sites or posted to a listserv without the copyright holder's express written permission. However, users may print, download, or email articles for individual use. 